\section{Embolic spinal cord infarction as a presentation of abdominal aortic aneurysm}

\author{
J F Fairhead MRCS D Phillips FRCS \\ A Handa FRCS FRCS(Ed)
}

J R Soc Med 2005;98:59-60

SECTION OF SURGERY, JUNE 2003

Embolization to the legs is a well-known presentation of abdominal aortic aneurysm. Embolization can also lead to spinal cord infarction.

\section{CASE HISTORY}

A man aged 72 experienced transient abdominal pain and became unable to move his legs. An ex-smoker, he had previously been fit and well apart from mild osteoarthritis. On examination his pulse and blood pressure were normal and he had a full complement of lower limb pulses. There was complete paralysis and paraesthesia in both legs below T12/L1. An erythematous, non-blanching, purpuric rash covered the entirety of both legs and extended circumferentially to $5 \mathrm{~cm}$ above the umbilicus. In the abdomen a nontender aneurysm was palpable, shown by thoracic and abdominal CT to be $7.8 \mathrm{~cm}$ in anteroposterior diameter, infrarenal, with no evidence of leak or dissection. There was extensive mural thrombus. The clinical diagnosis was of cutaneous and spinal cord embolization from the aortic aneurysm, and he was deemed to be at risk of further embolization. He was transferred to the operating theatre without delay and the aneurysm was repaired with a tube graft. There was a large amount of gritty, semi-liquid thrombus within the sac, which was seen to occlude the lumbar vessels. After removal of the thrombus, there was brisk back-bleeding from six of these vessels, which were oversewn. Clamp time was 55 minutes.

His postoperative recovery was uncomplicated; he was extubated in theatre, had a routine 24-hour admission to the intensive care unit and was eating and drinking normally by day five. He began to regain both sensory and motor function to his legs almost immediately. On the advice of a neurologist MRI was performed to exclude other treatable

Nuffield Department of Surgery, John Radcliffe Hospital, Headington, Oxford OX3 9DU, UK

Correspondence to: Mr Ashok Handa

E-mail: ashok.handa@surgery.ox.ac.uk causes of his motor and sensory loss. This revealed increased signal in the cord from T12 to L2, consistent with infarction. He underwent intensive physiotherapy and by eleven weeks he was able to walk a few steps. He was continent of faeces but on removal of his catheter he had urinary retention and incontinence despite bladder training; later he was successfully taught intermittent clean selfcatheterization. At the National Spinal Injuries Centre he received inpatient treatment followed by outpatient physiotherapy. At one year follow-up he is walking with callipers.

\section{COMMENT}

Several other associations of aneurysms with spinal cord infarction have been described. Dormal et al. described cord infarction as a complication of aneurysm repair or rupture, and from the published work reckoned the incidence to be $1-2 \%$ in all infrarenal surgery. The associated mortality was $50 \%$ in both ruptured and unruptured aneurysms. ${ }^{1}$ Thoraco-abdominal dissection is a well-known association, the likely mechanism of infarction being occlusion of the origins of major arteries feeding the spinal vasculature, such as the great anterior artery of Adamkiewicz at T10/12. Joo and Cummings describe a case of transient neurological syndrome as the only presentation of thoraco-abdominal dissection, with complete recovery after medical therapy. ${ }^{2}$ Similarly, local dissection can be a complication of infrarenal aneurysm. ${ }^{3}$ Acute aortic thrombosis may present as a painless paraplegia. Bolduc et al. describe two cases of acute thrombosis initially mimicking stroke in one patient and with relief of pain from a vulval abscess in another. Both patients were later found to have unsalvageable lower limbs. ${ }^{4}$ Direct erosion by a large aneurysm of the lumbar vertebral bodies in the setting of rheumatoid arthritis, leading to spinal cord compression, has also been described. ${ }^{5}$

The presentation we describe is different. The sudden loss of neurological function and non-blanching rash occurred preoperatively but there was no evidence of rupture, dissection or lower limb large artery occlusion. The intra-operative findings of liquid thrombus within the aneurysm sac are consistent with massive cholesterol embolization to the distal vasculature. Prompt surgery may have been critical in the prevention of further embolization and thus subsequent recovery of neurological function. Sudden paralysis and paraesthesia in such a context should prompt investigation for abdominal aneurysm and, if necessary, prompt surgical intervention.

\section{REFERENCES}

1 Dormal PA, Delberghe X, Roeland A. Infra-renal aortic aneurysm and spinal cord ischaemia. A new case and review of the literature. Acta Chir Belg 1995;95:136-8 
2 Joo JB, Cummings AJ. Acute thoracoabdominal aortic dissection presenting as painless, transient paralysis of the lower extremities: case report. J Emerg Med 2000;19:333-7

3 Joseph MG, Langsfield MA, Lusby RJ. Infra-renal aortic aneurysm; unusual cause of paraparesis. Aust NZ J Surg 1989;59:743-4

4 Bolduc ME, Clayson S, Madras PN. Acute aortic thrombosis presenting as painless paraplegia. J Cardiovasc Surg 1989;30:506-8

5 Latif S, Wasti A, Grundy DJ, Isdale A, Iveson JM. Direct erosion of lumbar spine by an abdominal aneurysm resulting in lumbar paralysis: an unusual presentation. Case report. Paraplegia 1995;33:480-1

\section{Puzzling hypercalcaemia: sarcoidosis without lung involvement}

\author{
A Fowler MRCP P Dargan MRCP \\ A Jones FRCP
}

J R Soc Med 2005;98:60-61

In a patient with unexplained hypercalcaemia, sarcoidosis is a possibility even if there is no overt pulmonary disease.

\section{CASE HISTORY}

A Caucasoid woman of 68 was seen after three weeks of confusion, polydipsia, anorexia, general malaise and weight loss. A life-long smoker of ten cigarettes a day, she had no medical history of note. On examination she was cachectic and dehydrated. Nothing else was found - in particular, no rashes, lymphadenopathy, or respiratory or neurological signs. Routine investigations revealed a lymphopenia of $0.6 \times 10^{9} / \mathrm{L}$ (full blood count otherwise normal), erythrocyte sedimentation rate $34 \mathrm{~mm} / \mathrm{h}$, normal serum electrolytes with mild renal impairment (urea $12.1 \mathrm{mmol} / \mathrm{L}$, creatinine $164 \mu \mathrm{mol} / \mathrm{L}$ ) and hypercalcaemia with a corrected serum total calcium of $3.56 \mathrm{mmol} / \mathrm{L}$ and phosphate $1.3 \mathrm{mmol} / \mathrm{L}$; alkaline phosphatase was $165 \mathrm{IU} / \mathrm{L}$, alanine aminotransferase $44 \mathrm{IU} / \mathrm{L}$, gammaglutamyltransferase $81 \mathrm{IU} / \mathrm{L}$, and albumin $30 \mathrm{~g} / \mathrm{L}$. Her chest radiograph was normal.

The initial clinical diagnosis was hypercalcaemia secondary to malignant disease. Further testing revealed a normal mammogram, a normal parathyroid hormone $(\mathrm{PTH})$ of $25 \mathrm{ng} / \mathrm{L}$ (normal range 10-65), parathyroidrelated peptide (PTHrP) $1.0 \mathrm{pmol} / \mathrm{L} \quad(0.1-1.8)$ and 25 -hydroxyvitamin-D $68 \mathrm{nmol} / \mathrm{L}(20-100)$ but a raised

Department of Medicine, St Thomas' Hospital, London SE1 7EH, UK

Correspondence to: Dr A Fowler

E-mail: afowler@doctors.org.uk
1,25-dihydroxyvitamin-D of $144 \mathrm{pmol} / \mathrm{L}$ (20-120). Serum protein electrophoresis was normal and urine examination was negative for Bence Jones protein. After rehydration with intravenous colloid her renal function returned to normal over four weeks. However, she remained symptomatic with a serum calcium concentration of greater than $3.7 \mathrm{mmol} / \mathrm{L}$. She was treated with four intravenous doses of pamidronate $(30 \mathrm{mg}, 60 \mathrm{mg}, 90 \mathrm{mg}, 30 \mathrm{mg}$ ) over eight weeks, during which her calcium peaked at $4.2 \mathrm{mmol} / \mathrm{L}$ (Figure 1).

Abdominal CT revealed minimal dilatation of the left hepatic ducts and portahepatic lymphadenopathy. A CTguided biopsy of these nodes showed non-caseating granulomata. She had a grade zero Heaf test. Highresolution CT of the chest revealed bullous emphysema in the apices but no radiological pulmonary features suggestive of sarcoidosis; however, her serum angiotensin converting enzyme (sACE) was raised at $211 \mathrm{IU} / \mathrm{L}$ (27-82).

Sarcoidosis was diagnosed and she was treated with oral prednisolone $40 \mathrm{mg}$ daily. Symptoms quickly resolved; serum calcium became normal within two weeks and sACE within two months. Twenty months after discharge she was taking $5 \mathrm{mg}$ prednisolone daily and symptom-free; her serum calcium was normal $(2.55 \mathrm{mmol} / \mathrm{L})$.

\section{COMMENT}

Hypercalcaemia, although seen in $10-20 \%$ of patients with sarcoidosis, is rare in the absence of pulmonary involvement. ${ }^{1}$ A search of EMBASE and Medline yielded only ten such cases. The present case illustrates the difficulty of distinguishing between causes of hypercalcaemia. Though not a diagnostic marker of sarcoidosis, a high ACE is a useful pointer. ${ }^{2}$

The mechanism of hypercalcaemia in sarcoidosis is not fully understood. Calcium homoeostasis is controlled mainly by levels of vitamin-D, PTH and calcitonin. 1,25dihydroxycholecalciferol $\left(1,25(\mathrm{OH})_{2} \mathrm{D}_{3}\right)$, the most active form of vitamin-D, is ultimately formed in the kidney following $1 \alpha$-hydroxylation of 25-hydroxycholecalciferol $\left(25[\mathrm{OH}]_{2} \mathrm{D}_{3}\right)$ by the enzyme $1 \alpha$-hydroxylase. $1,25(\mathrm{OH})_{2} \mathrm{D}_{3}$ acts to increase gastrointestinal absorption of calcium and phosphate whilst also stimulating osteoclastmediated bone resorption. ${ }^{3}$ Studies showing increased circulating concentrations of $1,25(\mathrm{OH})_{2} \mathrm{D}_{3}$ in patients with sarcoidosis and hypercalcaemia led to the hypothesis that the cause was related to abnormal vitamin-D metabolism. One theory suggests that increased $1,25(\mathrm{OH})_{2} \mathrm{D}_{3}$ synthesis is caused by activated pulmonary macrophages in granulomatous tissue. ${ }^{1}$ This is validated by studies showing generation of $1,25(\mathrm{OH})_{2} \mathrm{D}_{3}$ from homogenates of alveolar macrophages from patients with sarcoidosis. ${ }^{4}$ Furthermore, an increase in $1 \alpha$-hydroxylase mRNA expression has been 